\title{
A three-year longitudinal study of retinal function and structure in patients with multiple sclerosis
}

\author{
James V. M. Hanson (D) Mei-Yee Ng • Helen K. Hayward-Koennecke • \\ Sven Schippling $\cdot$ Kelly A. Reeve $\cdot$ Christina Gerth-Kahlert
}

Received: 22 April 2021 / Accepted: 15 September 2021 / Published online: 27 October 2021

(C) The Author(s) 2021

\begin{abstract}
Background Researchers have in recent years begun to investigate ophthalmological manifestations of multiple sclerosis (MS) other than optic neuritis $(\mathrm{ON})$, and it is now clear that changes to retinal function (measured using the electroretinogram, ERG) and structure (measured using optical coherence tomography, OCT) are found in MS patients irrespective of prior ON episodes. ERG results are consistent with dysfunctional bipolar cells, as in other
\end{abstract}

Supplementary Information The online version contains supplementary material available at https://doi.org/10.1007/ s10633-021-09855-7.

\section{J. V. M. Hanson $(\bowtie) \cdot$ C. Gerth-Kahlert}

Department of Ophthalmology, University Hospital

Zurich and University of Zurich, Frauenklinikstrasse 24,

8091 Zurich, Switzerland

e-mail: james.hanson@usz.ch

C. Gerth-Kahlert

e-mail: christina.gerth-kahlert@usz.ch

M.-Y. Ng

Masters Program in Biostatistics, University of Zurich, Hirschengraben 84, 8001 Zurich, Switzerland

e-mail: meiyee.ng@uzh.ch

H. K. Hayward-Koennecke

Clinic for Neurology, Neuroimmunology and Multiple

Sclerosis Research, University Hospital Zurich and

University of Zurich, Frauenklinikstrasse 26, 8091 Zurich,

Switzerland

e-mail: helen.hayward-koennecke@usz.ch autoimmune diseases. To date, studies have presented only cross-sectional data regarding ERG and OCT. We, therefore, studied the longitudinal course of ERG and OCT in patients with MS, as well as the effect of disability changes and non-ON clinical relapses on these functional and structural measures.

Methods MS patients $(n=23)$ participating in an ongoing longitudinal observational study were invited to take part in a 3-year ophthalmological substudy. ERG and OCT were performed, and measures of MSrelated disability and relapse history were obtained. Study visits were repeated annually. ERG peak times, rod b-wave amplitude, mixed rod/cone and cone b-/a-

\author{
S. Schippling \\ Multimodal Imaging in Neuroimmunological Diseases \\ (MINDS), University Hospital Zurich and University of \\ Zurich, Frauenklinikstrasse 26, 8091 Zurich, Switzerland \\ e-mail: sven.schippling@gmx.de \\ K. A. Reeve \\ Institute for Epidemiology, Biostatistics, and Prevention, \\ Department of Biostatistics, University of Zurich, \\ Hirschengraben 84, 8001 Zurich, Switzerland \\ e-mail: kelly.reeve@uzh.ch
}


wave amplitude ratios, thickness of the peripapillary retinal nerve fibre layer, and volumes of the segmented retinal layers/complexes were analysed. Using generalised estimating equation models adjusted for age, $\mathrm{ON}$, and MS treatment status, we assessed changes to ERG and OCT over the study duration, the effect of changes in disability and recent non-ON MS relapses on ERG and OCT, and the effect of selected OCT parameters on corresponding ERG parameters.

Results At the group level, small fluctuations of several ERG peak times were recorded, with OCT values remaining stable. Increased disability between visits was associated with significant prolongation of mixed rod-cone ERG b-wave peak times. No evidence of associations between OCT and ERG parameters was observed.

Conclusions Retinal bipolar cell function may be affected by changes in disability in patients with MS; however, recent non-ON MS clinical relapses appear not to affect ERG or OCT results. As ERG changes in MS patients over 3 years are likely to be small and of uncertain clinical relevance, longitudinal studies of retinal function in MS should be planned over an extended period.

Keywords Multiple sclerosis - Electroretinogram · Optical coherence tomography $\cdot$ Retina $\cdot$ Bipolar cells

\section{Introduction}

Multiple sclerosis (MS) is a chronic neurological autoimmune disease characterised by inflammatory demyelination and neurodegeneration within the central nervous system (CNS). In approximately $90 \%$ of cases, MS manifests with a first clinical episode suggestive of demyelination in the CNS without the evidence of dissemination of disease activity in time and space required for a diagnosis of MS [1]; such episodes are referred to as clinically isolated syndrome (CIS) [1]. Despite a heterogeneous clinical presentation, the afferent visual pathway is frequently affected in patients with MS and CIS, with optic neuritis (ON) being particularly common [2]. The high prevalence of visual system involvement, together with the accessibility of the retina as the only location where unmyelinated axons and neurons can be examined in vivo in humans, has generated increasing interest in the afferent visual pathway as a model for MS [3, 4]. Retinal function and structure can be measured with the full-field (ganzfeld) electroretinogram (ERG) and with optical coherence tomography (OCT), respectively. Photoreceptor function is captured predominantly by the ERG a-wave, with the ERG b-wave and flicker response reflecting predominantly bipolar (post-receptoral, pre-ganglionic) function $[5,6]$. Structural examination has been facilitated by the development of software tools enabling the demarcation and quantitative analysis of the retinal layers ('segmentation') from OCT scans.

In recent years, the ERG has enabled the documentation of outer retinal dysfunction in patients with MS, particularly affecting bipolar cells driven wholly or partly by the cone photoreceptors [7-12]. This dysfunction, evidenced by prolongation of the ERG b-wave and/or $30 \mathrm{~Hz}$ flicker response peak time, appears independent of a history of ON $[7,11]$ and has been demonstrated in cohorts where eyes with $\mathrm{ON}$ were excluded [8-10]. Bipolar dysfunction has also been documented in other autoimmune diseases [13-21]. Delayed ERG a-wave peak times have also been documented [7, 9-12], although not by all investigators $[8,22]$. Using OCT in addition to ERG, we have demonstrated that the abnormal ERG-derived measures of bipolar cell function in patients with MS are uncorrelated with structural measures of their presumed retinal origin, the inner nuclear layer (INL) [7], consistent with dysfunctional, but not atrophic, bipolar cells [7, 11]. Despite these robust crosssectional findings, documented by a number of groups working independently, longitudinal functional data regarding the bipolar cells and INL in patients with MS are currently sparse.

Longitudinal OCT-derived retinal structural studies in patients with MS have recorded accelerated thinning of the retinal nerve fibre layer (RNFL) and ganglion cell-inner plexiform layer (GCIPL) relative to control subjects [23-26]. Whilst ON leads to variable atrophy of RNFL and GCIPL, this transient insult does not significantly affect the underlying rate of insidious inner retinal thinning [24, 25]. A recent multi-centre study focussing on INL documented thickening (as opposed to thinning) after $\mathrm{ON}$ or nonON clinical relapses [27], compatible with earlier findings describing increased INL thickness in patients with active MS [28]. Conversely, some authors have reported mild longitudinal INL thinning in patients 
with MS [26]. In summary, INL findings in MS appear to be more variable than ERG results and, importantly, confounded by ON. Conversely, ERG findings are broadly consistent between different research groups and appear to be unaffected by ON (as discussed above). The extent to which ERG findings reflect clinical changes in MS status remains unknown.

With these factors in mind, we set out to longitudinally measure ERG and OCT in patients with MS and CIS, determine the relationships between these functional and structural outcome measures, and investigate the influence of clinical relapses and changes in global disability on retinal function and structure.

\section{Methods}

All subjects were participants in an ongoing longitudinal study of MS at the University Hospital Zurich who consented in writing to participate in a three-year longitudinal ophthalmological substudy. Inclusion criteria for the substudy were: confirmed diagnosis of MS or CIS according to contemporary criteria [29], and age at enrolment 18-65 years. Exclusion criteria were: refractive errors $>6$ dioptres, co-existing ocular or neurological disease other than MS, and diabetes mellitus. The study adhered to the tenets of the Declaration of Helsinki and was approved by the Cantonal Ethics Committee of Zurich (ECNo.2013-0001). Examinations consisted of: best-corrected high- and low-contrast visual acuity using Early Treatment Diabetic Retinopathy Study (ETDRS) and $2.5 \%$ contrast Sloan charts, respectively; anterior segment and mydriatic fundus examination by a senior ophthalmologist, OCT, and ERG. Following baseline examinations, this battery of tests was repeated on an annual basis for three years, making a total of four examinations per subject. Examinations also included measurement of the visual evoked potentials, multifocal ERG, pattern ERG, and photopic negative response; however, the results of these examinations were not analysed longitudinally due to our focus on measures of panretinal bipolar function. Expanded Disability Status Scale (EDSS) score and relapse history were obtained by neurological examination and chart review by experienced neurologists. As EDSS values were $<5.5$ throughout the study for all patients, a change in EDSS of 1.0 or more between examinations was considered clinically meaningful [30]. All examinations took place over the period June 2014-October 2019.

\section{ERG}

ERG was recorded using gold-plated skin electrodes and single-use DTL (Dawson et al.) recording electrodes (Diagnosys LLC, Lowell MA, U.S.A) according to contemporary standards of the International Society for Clinical Electrophysiology of Vision [31] on an Espion system (Diagnosys LLC), which was annually calibrated throughout the duration of the study. Medical mydriasis was accomplished using topical $0.5 \%$ tropicamide and 5\% phenylephrine. Topical $0.4 \%$ oxybuprocaine was instilled prior to positioning the DTL electrodes. All ERG measurements were made by a single experienced operator (author JVMH) using identical electrodes and with the DTL thread positioned horizontally at the lower lid margin. Recordings were made with a bandwidth of $0.3-300 \mathrm{~Hz}$ and a sampling rate of $2 \mathrm{kHz}$.

After $20 \mathrm{~min}$ of dark adaptation, patients were presented with $0.01 \mathrm{~cd} / \mathrm{m}^{2}$ flashes ('rod') followed by $3.0 \mathrm{~cd} / \mathrm{m}^{2}$ flashes ('rod-cone'). Following these measurements, patients were adapted to a rod-bleaching $30 \mathrm{~cd} / \mathrm{m}^{2}$ light for $10 \mathrm{~min}$ before being presented with $3.0 \mathrm{~cd} / \mathrm{m}^{2}$ light, both flickering $(30 \mathrm{~Hz}$ frequency; 'flicker') and single flashes ('cone') against a $30 \mathrm{~cd} /$ $\mathrm{m}^{2}$ background. All stimuli were presented via a fullfield stimulator with diffusor, of $4 \mathrm{~ms}$ duration, and composed of white light. Multiple responses were recorded for each condition to verify reproducibility, which were then averaged.

From the ERG, the a-wave, b-wave, and flicker peak times and amplitudes were ascertained for each eye and each stimulus condition with the exception of the dark-adapted (DA) $0.01 \mathrm{~cd} / \mathrm{m}^{2}$ ('rod') a-wave, which is not recommended for quantitative analysis [31]. Ratios of the rod-cone and cone b-wave/a-wave amplitudes (a normalised measure of bipolar function) were calculated. All ISCEV standard [31] ERG peak times were included in our analysis. The rod b-wave amplitude was also analysed, due to previous work suggesting longitudinal changes to this parameter (and, to a lesser extent, other ERG amplitudes) in MS patients [10]. Other ISCEV standard ERG amplitudes were not analysed due to the predominance of normal findings in previous MS studies [7-12], and because 
the known dependence of amplitudes (but not peak times) on DTL position [32,33] could have potentially confounded longitudinal measures of ERG amplitudes. Instead, we captured ERG amplitudes using the rod-cone and cone b-wave/a-wave ratios.

\section{OCT}

All OCT scans were acquired in a darkened room using a Spectralis device (Heidelberg Engineering, Heidelberg, Germany. High resolution circumpapillary scans $\left(12^{\circ}\right.$ diameter; 100 Automatic Real-time Tracking [ART]) were aligned to the visible centre of the optic nerve head, whilst high resolution volume scans $\left(30^{\circ}\right.$ vertical by $15^{\circ}$ horizontal, 19 vertically oriented sections separated by $240 \mu \mathrm{m}, 25$ ART) were centred on the fovea. Baseline scans were set as the reference within the Heidelberg software, with scans at visits 2, 3, and 4 acquired in 'follow-up' mode to ensure precise alignment of subsequent scans with the same anatomical landmarks as at baseline. After ensuring that all acquired OCT scans were of acceptable quality as defined by the OSCAR-IB criteria [34], the volume scans were automatically segmented and manually verified and corrected using proprietary software (Heidelberg Engineering). This enabled visualisation and quantification of the macular ganglion cell-inner plexiform layer complex (GCIP), INL, outer plexiform layer (OPL), ONL, and outer retinal layers (ORL; defined proximally by the external limiting membrane [ELM] and distally by Bruch's membrane [BM], and therefore comprising mainly the photoreceptors) for each eye. Each of the macular OCT parameters was summarised as the volume (in $\mathrm{mm}^{3}$ ) of each layer or complex measured over a $3.45 \mathrm{~mm}$ diameter circle. RNFL thickness measurements were obtained from the circumpapillary OCT scan; the global thickness (RNFL-G), averaged from all sectoral measurements, was analysed, along with thickness in the temporal (RNFL-T) and papillomacular bundle (RNFL-PMB) sectors. All OCT scans were acquired and verified by a single experienced operator (author JVMH).

\section{Statistical Analyses}

Specific goals of the study were as follows:

- To ascertain whether ERG and OCT parameters changed over the 3-year study duration
- To investigate whether changes to MS clinical status (EDSS score; MS relapse within the previous 12 months) were associated with changes in ERG and OCT parameters

- To evaluate whether changes in OCT parameters (INL; ONL and ORL) were related to changes in the relevant ERG outcome measures (ERG b-wave and flicker peak times, ERG b/a wave ratios; ERG a-wave peak times) over the study duration

Both eyes of each patient were analysed. Generalised estimating equation (GEE) models [35] assuming independent correlation structure were used in order to account for both longitudinal correlations and correlations between measurements of different eyes of the same patients. All models were adjusted for age, previous ON, and MS treatment status (treated/ untreated). ON history was determined for each eye separately, whereas age, EDSS score, MS relapse history, and MS treatment status were identical for both eyes. $P$ values were corrected for multiple comparisons using the method of Benjamini and Hochberg [36]. Corrected $p$ values $<0.05$ were considered significant. All analyses were performed in $\mathrm{R}$ version 3.5.3 [37] using the library geepack version 1.3.1 [38]. Graphs were created initially in $R$, with Figs. 2 and 3 being assembled from individual graphs in Affinity Designer version 1.7.3.481 (Serif [Europe] Ltd, Nottingham, U.K.).

\section{Results}

After dropouts, longitudinal data from 23 patients aged 23-54 years were available for analysis. 14 patients had relapsing-remitting MS (RRMS), eight CIS, and one primary progressive MS (PPMS). Median disease duration, defined as time since first MS/CIS symptoms, was 20 months. One eye of a single patient was excluded due to a large-angle exotropia, meaning that 45 eyes were analysed. (However, OCT of a single patient at baseline failed quality control and was excluded from analysis.) Reliable HCVA and LCVA values could not be obtained at baseline for both eyes of a single patient due to an accommodative spasm. It was not possible to quantify HCVA and/or LCVA at baseline in a small number of additional eyes (HCVA: $n=1$; LCVA: $n=2$ ) with previous $\mathrm{ON}$, as the patients were unable 
to read any letters on the test charts. 16 eyes had previous ON, with three of these having $\mathrm{ON}$ within the 12 months prior to baseline; one patient experienced unilateral ON during the course of the study. Seven patients experienced non-ON clinical relapses over the study period. Of the eight patients with CIS at baseline, five had converted to MS by the end of the study. Demographic details of the patient cohort at baseline are given in Table 1 .

Although the majority of patients attended all examinations, a minority were unable to attend the second and/or third examinations for reasons such as pregnancy/childbirth or a change in location. However, all 23 patients attended both the first and last examinations, permitting analysis of functional and structural retinal changes over a three-year period. OCT was not possible in one eye of a single patient at visit 3 only, due to severe visual loss after $\mathrm{ON}$ and consequent malfixation. The number of eyes analysed at each visit are recorded in Tables S1 (ERG) and S2 (OCT).

Illustrative cross-sectional ERG waveforms from a participant with MS are shown, along with those of a healthy individual, in Fig. 1a-d. Mean and median ERG and OCT data at each visit are provided in Tables S1 and S2, respectively. The results of the GEE models analysing ERG and OCT findings over time are displayed in Table 2 and Fig. 2, and Table S3 and
Fig. 3, respectively. At the group level, we recorded significant changes in the following ERG parameters (all relative to the visit 1 baseline): DA 3.0 a-wave peak time (visits 2, 3, and 4), LA 3.0 a-wave peak time (visit 2), and LA 3.0 b-wave peak time (visit 2). We did not observe any significant changes in other ERG parameters, or in any OCT parameters, over the study duration.

Tables 3 and S4 show the results of GEE models analysing the effects of EDSS changes and clinical relapses in the preceding 12 months on ERG and OCT parameters, respectively. We observed a significant positive effect of EDSS changes on DA 3.0 b-wave peak times, with an increase in EDSS being associated with a prolongation of the ERG peak time of $3.65 \mathrm{~ms}$ (95\%CI 1.78-5.53 ms). Throughout the study, eight patients experienced a significant change in EDSS at a total of 16 visits. All other effects were nonsignificant.

Finally, Tables S5 and S6 show the results of GEE models analysing the relationships between OCT parameters and their corresponding ERG parameters. All effects were non-significant.
Table 1 Characteristics of the patient cohort at baseline. CIS, clinically isolated syndrome; EDSS, Expanded Disability Status Scale; HCVA, high-contrast visual acuity; IQR, interquartile range; LCVA, low-contrast visual acuity; MAR, minimum angle of resolution; ON, optic neuritis; PPMS, primary progressive multiple sclerosis; RRMS, relapsing-remitting multiple sclerosis; SD, standard deviation. Disease duration is defined as the time since initial MS/CIS symptoms

\begin{tabular}{lll}
\hline & Level & Value \\
\hline Patients (total eyes analysed) & & $23(45)$ \\
Diagnosis & RRMS & $14(61 \%)$ \\
& CIS & $8(35 \%)$ \\
& PPMS & $1(4 \%)$ \\
Treatment & No & $12(52.2 \%)$ \\
& Yes & $11(47.8 \%)$ \\
Relapse (previous 12 months) & No & $16(69.6 \%)$ \\
& Yes & $7(30.4 \%)$ \\
ON & No & 29 eyes $(64.4 \%)$ \\
& Yes & 16 eyes $(35.6 \%)$ \\
ON (previous 12 months) & No & 42 eyes $(93.3 \%)$ \\
& Yes & 3 eyes $(6.7 \%)$ \\
Age (years) (median [IQR]; mean (SD)) & & $38.00[31.00,43.50] ; 37.13(8.97)$ \\
Disease duration (months) (median [IQR]; mean (SD)) & $20.00[12.00,72.00] ; 59.83$ (82.16) \\
EDSS (median [minimum, maximum]) & & $1.5[0,4]$ \\
HCVA (logMAR) (median [IQR]; mean (SD)) & $-0.09[-0.13,-0.06] ;-0.09$ (0.07) \\
2.5\% LCVA (logMAR) (median [IQR]; mean (SD)) & $0.42[0.36,0.57] ; 0.46(0.16)$ \\
\hline
\end{tabular}



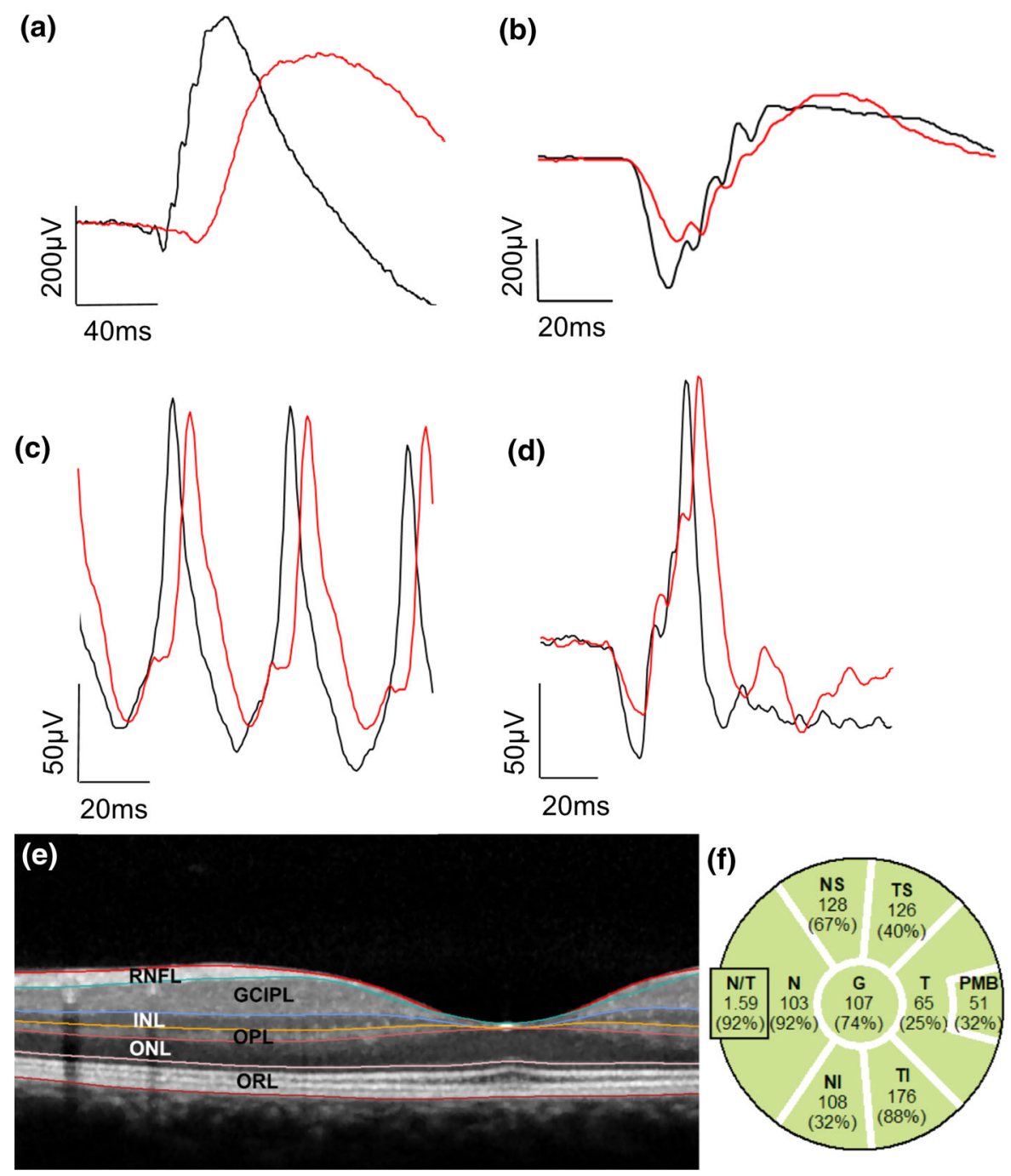

Fig. 1 a-f. Representative ERG waveforms (a-d) and illustration of the OCT layers and complexes analysed. ERG waveforms are shown for a healthy individual (black curves) and a patient with MS (red curves) following dark-adapted 0.01 ('rod'), dark-adapted 3.0 ('rod-cone'), light-adapted $3.030 \mathrm{~Hz}$ ('flicker'), and light-adapted 3.0 single flash ('cone') stimulation (a-d, respectively). For all conditions, $\mathrm{x}$-axis scales represent time since stimulus onset in milliseconds (ms), and $y$-axis scales amplitudes in $\mu \mathrm{V}$. Note that no normative patients were included in the present study; the waveforms are shown to illustrate cross-sectional findings in patients with MS, rather than the longitudinal course of ERG measurements described in this work. A segmented OCT macular scan with the relevant layers and complexes highlighted (e) and the circumpapillary

\section{Discussion}

Outer retinal function, as measured using the ERG, appears broadly stable in patients with MS and CIS thickness analysis of RNFL (f) are displayed. Only G, T, and PMB were included in the analyses. The values for each sector/ quadrant show the thickness in $\mu \mathrm{m}$, with the figure in brackets showing the corresponding percentile of age-matched normal values. G, global average of RNFL thickness; GCIPL, ganglion cell-inner plexiform layer; INL, inner nuclear layer; $\mathrm{N}$, nasal quadrant of RNFL; NI, nasal inferior sector of RNFL; NS, nasal superior sector of RNFL; N/T, ratio of nasal/temporal RNFL thickness; ONL, outer nuclear layer; OPL, outer plexiform layer; ORL, outer retinal layers; PMB, papillomacular bundle; RNFL, retinal nerve fibre layer; S, superior quadrant of RNFL; $\mathrm{T}$, temporal quadrant of RNFL; TI, temporal inferior sector of RNFL; TS, temporal superior sector of RNFL

over a three-year period at the group level. Although three ERG peak time parameters differed significantly relative to baseline (Table 2), the absolute differences were typically less than the temporal resolution of the 
Table 2 Results of GEE models describing changes in ERG parameters over the study duration

\begin{tabular}{|c|c|c|c|c|}
\hline ERG Variable & Covariate & Coefficient & $95 \% \mathrm{CI}$ & $\mathrm{P}$ \\
\hline \multirow[t]{4}{*}{ DA 0.01 ('Rod') AMP } & Intercept & 394.94 & 309.39 to 480.48 & NA \\
\hline & Visit 2 & -9.56 & -36.86 to 17.74 & 0.83 \\
\hline & Visit 3 & -29.85 & -57.3 to -2.41 & 0.14 \\
\hline & Visit 4 & -5.77 & -27.38 to 15.85 & 0.86 \\
\hline \multirow[t]{4}{*}{ DA 0.01 ('Rod') PEAK } & Intercept & 72.15 & 63.48 to 80.81 & NA \\
\hline & Visit 2 & -2.30 & -6.29 to 1.7 & 0.50 \\
\hline & Visit 3 & -0.46 & -3.76 to 2.84 & 0.93 \\
\hline & Visit 4 & 0.43 & -3.05 to 3.91 & 0.93 \\
\hline \multirow[t]{4}{*}{ DA 3.0 (Rod-Cone') a-wave PEAK } & Intercept & 13.96 & 13.13 to 14.79 & NA \\
\hline & Visit 2 & 0.36 & 0.1 to 0.62 & $\mathbf{0 . 0 3 7}$ \\
\hline & Visit 3 & 0.36 & 0.15 to 0.56 & 0.005 \\
\hline & Visit 4 & 0.43 & 0.25 to 0.61 & 0.0001 \\
\hline \multirow[t]{4}{*}{ DA 3.0 ('Rod-Cone') b-wave PEAK } & Intercept & 56.11 & 50.69 to 61.53 & NA \\
\hline & Visit 2 & 0.20 & -0.76 to 1.17 & 0.92 \\
\hline & Visit 3 & -0.26 & -1.07 to 0.54 & 0.83 \\
\hline & Visit 4 & 0.54 & -0.5 to 1.58 & 0.55 \\
\hline \multirow[t]{4}{*}{ DA 3.0 b/a-wave RATIO } & Intercept & 0.77 & 0.19 to 1.35 & NA \\
\hline & Visit 2 & 0.00 & -0.08 to 0.08 & 0.97 \\
\hline & Visit 3 & 0.01 & -0.06 to 0.08 & 0.92 \\
\hline & Visit 4 & -0.02 & -0.12 to 0.07 & 0.86 \\
\hline \multirow[t]{4}{*}{ LA 30 Hz Flicker PEAK } & Intercept & 27.16 & 22.67 to 31.66 & NA \\
\hline & Visit 2 & 0.63 & -0.02 to 1.29 & 0.20 \\
\hline & Visit 3 & -0.03 & -0.88 to 0.82 & 0.97 \\
\hline & Visit 4 & -0.65 & -1.52 to 0.22 & 0.33 \\
\hline \multirow[t]{4}{*}{ LA 3.0 ('Cone') a-wave PEAK } & Intercept & 13.83 & 13 to 14.67 & NA \\
\hline & Visit 2 & 0.33 & 0.16 to 0.49 & 0.001 \\
\hline & Visit 3 & 0.17 & -0.06 to 0.39 & 0.33 \\
\hline & Visit 4 & 0.14 & -0.09 to 0.37 & 0.50 \\
\hline \multirow[t]{4}{*}{ LA 3.0 ('Cone') b-wave PEAK } & Intercept & 31.04 & 26.72 to 35.35 & NA \\
\hline & Visit 2 & 1.04 & 0.34 to 1.75 & 0.025 \\
\hline & Visit 3 & -0.02 & -1 to 0.96 & 0.97 \\
\hline & Visit 4 & -0.85 & -1.84 to 0.13 & 0.27 \\
\hline \multirow[t]{4}{*}{ LA 3.0 b/a-wave RATIO } & Intercept & 2.64 & 1.58 to 3.7 & NA \\
\hline & Visit 2 & -0.20 & -0.46 to 0.06 & 0.33 \\
\hline & Visit 3 & 0.03 & -0.24 to 0.3 & 0.93 \\
\hline & Visit 4 & 0.34 & 0.02 to 0.66 & 0.14 \\
\hline
\end{tabular}

(Fig. 2, Table S1). However, we cannot exclude the possibility that the heterogeneity of our patient cohort, reflective of the disease heterogeneity of MS generally, may have masked subtle changes to ERG parameters in different patient subpopulations. On a similar note, it is possible that differences in the disease course between patients may have contributed to our lack of significant findings (by different patterns 
Table 3 Results of GEE models describing the effect of EDSS changes and recent ( $<12$ months) clinical relapses on ERG parameters over the study duration

\begin{tabular}{llccc}
\hline ERG variable & Covariate & Coefficient & $95 \%$ CI & P \\
\hline DA 0.01 ('Rod') AMP & EDSS & 12.17 & -33.64 to 57.97 & 0.77 \\
& Relapse & 17.19 & -15.72 to 50.11 & 0.61 \\
DA 0.01 ('Rod') PEAK & EDSS & 2.07 & -3.35 to 7.49 & 0.71 \\
& Relapse & 3.00 & -0.55 to 6.55 & 0.37 \\
DA 3.0 ('Rod-Cone') a-wave PEAK & EDSS & 0.10 & -0.22 to 0.41 & 0.76 \\
& Relapse & 0.02 & -0.25 to 0.29 & 0.89 \\
DA 3.0 ('Rod-Cone') b-wave PEAK & EDSS & 3.65 & 1.78 to 5.53 & $\mathbf{0 . 0 0 4}$ \\
& Relapse & 0.99 & -0.99 to 2.97 & 0.61 \\
DA 3.0 b/a-wave RATIO & EDSS & -0.20 & -0.42 to 0.03 & 0.37 \\
LA 30 Hz Flicker PEAK & Relapse & 0.09 & -0.02 to 0.19 & 0.37 \\
& EDSS & 1.05 & -0.54 to 2.63 & 0.50 \\
LA 3.0 ('Cone') a-wave PEAK & Relapse & 0.14 & -1.04 to 1.32 & 0.89 \\
& EDSS & 0.42 & 0.09 to 0.76 & 0.20 \\
LA 3.0 ('Cone') b-wave PEAK & Relapse & 0.11 & -0.18 to 0.41 & 0.71 \\
& EDSS & 0.86 & -0.7 to 2.41 & 0.60 \\
LA 3.0 b/a-wave RATIO & Relapse & -0.25 & -1.58 to 1.08 & 0.83 \\
& EDSS & -0.36 & -0.71 to -0.02 & 0.36 \\
& Relapse & 0.13 & -0.11 to 0.37 & 0.60 \\
\hline
\end{tabular}

The coefficients and $95 \%$ CIs for each ERG variable quantify the effect of the covariates on the variable. Corrected $p$ values $<0.05$, suggesting a significant influence of the covariate on the relevant ERG parameter, are highlighted in bold. CI, confidence intervals; DA, dark adapted; EDSS, Expanded Disability Status Scale; LA, light adapted. used, and fewer ERG examinations per patient [2 vs. 4 in the present work]) preclude a detailed comparison with the present work. An additional challenge in comparing the two studies is that we analysed only rod b-wave, rather than all standard ERG, amplitudes; however, our normalised measures of rod-cone and cone ERG amplitude (namely the b-/a-wave ratios) did not change significantly over the study period.

We recorded stable OCT parameters throughout the study at the group level. Whilst other authors have also recorded stable RNFL-G (but not RNFL-T or RNFLPMB) over this period [23], thinning of this parameter seems to be more commonly reported $[25,27,39]$. The majority of previous longitudinal studies have not presented analyses of RNFL-T and RNFL-PMB $[25,27,39]$. Our lack of significant findings in this respect may be partially artefactual due to our modestly sized cohort, but likely also reflects the fact that only one of our patients experienced ON during the course of the study, as acute $\mathrm{ON}$ causes a reduction in RNFL thickness [40, 41]. As with RNFL, GCIP thickness has been found by other authors to decline longitudinally in patients with MS [23, 25, 27, 39], although not necessarily more so than in healthy control subjects [42]. Also as with RNFL, we interpret our lack of significant findings in this regard as a 


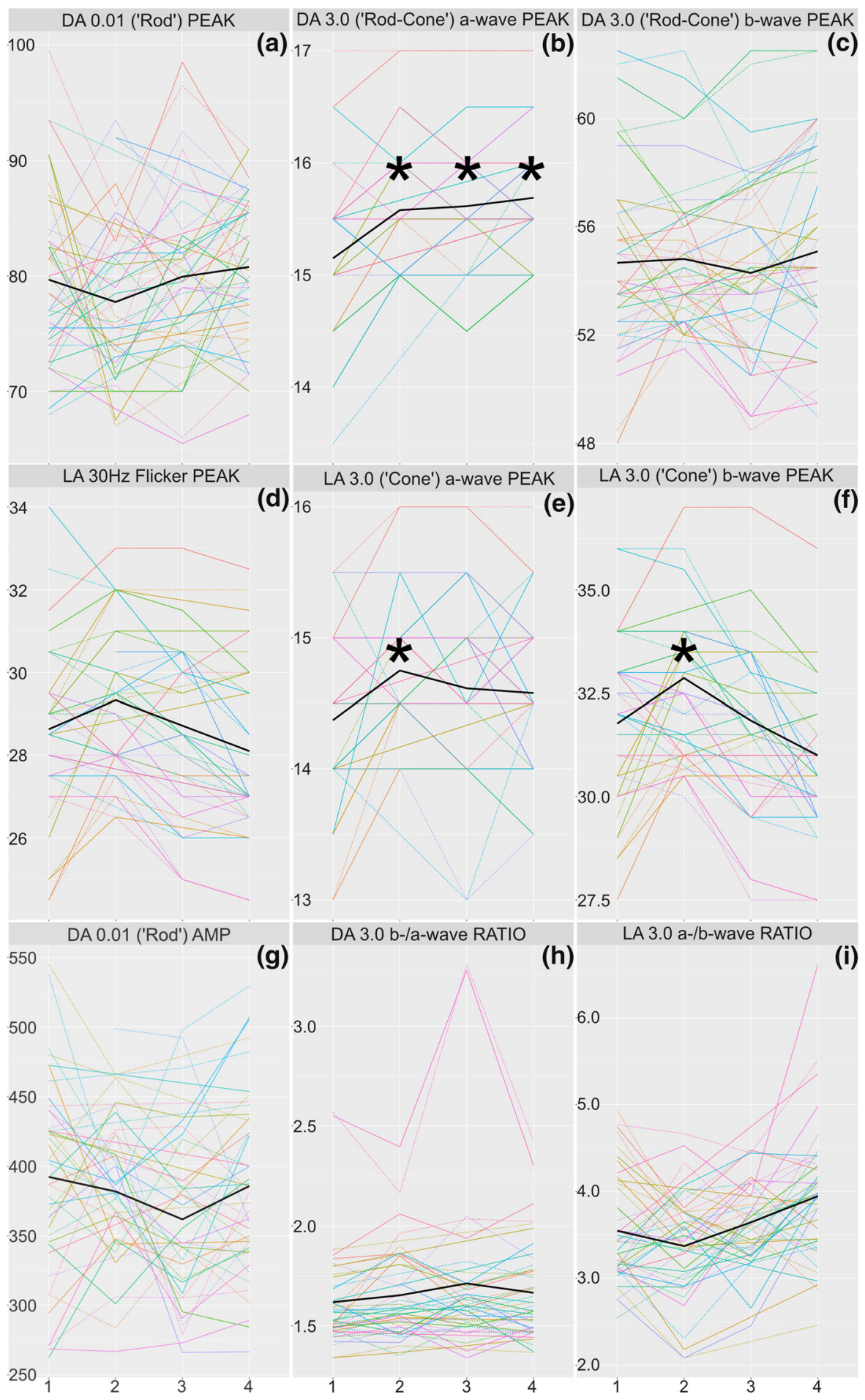

Fig. 2 a-i Plot showing analysed ISCEV standard ERG parameters over the study duration, including all peak times ('PEAK'; a-f), DA 0.01 amplitude ('AMP'; g), and DA 3.0 and LA 3.0 b-/a-wave ratios ('RATIO'; h-i). Coloured lines show the parameters of individual eyes (right eyes: dashed lines; left eyes: solid lines). Individual patients are represented with different colours. Solid black lines show results at the level of the entire cohort (see also Table 2). Results at individual visits which differ significantly from baseline (visit 1) are highlighted with black asterisks. DA, dark adapted; LA, light adapted 
consequence of our sample size and the paucity of ON events over the course of the study. INL appears to remain stable longitudinally in eyes without recent $\mathrm{ON}$ $[25,27]$, as we observed here, but increases in thickness following ON [27], a finding which may also affect the contralateral (non-ON) eye [41]. These previous findings are compatible with our results describing stable INL, as only one of our patients experienced ON during the study period. We are unaware of previous longitudinal OCT studies of the retina distal to INL in patients with MS and CIS, and so our data represent the first evidence suggesting that OPL, ONL, and ORL may remain stable over three years in these patients. The lack of correlation between OCT results and corresponding ERG peak times also mirrors previous cross-sectional results [7]. Variability at the individual patient/eye level was observable for INL and OPL (Fig. 3); however, extrapolation of OCT findings at the group level to individual patients is considered problematic due to the resolution of commercial OCT devices $(3-7 \mu \mathrm{m})$ being frequently greater than individual changes in retinal layer thicknesses [43]. With this in mind, we note that INL and OPL are the thinnest of the retinal layers studied here and thus may be the most challenging to reliably quantify longitudinally.

Our finding that increases in global disability (measured by EDSS) are associated with prolongation of DA 3.0 ('rod-cone') ERG b-wave peak times provides the first tentative evidence of a potential link between retinal bipolar cell function and MS disease activity. Despite this finding being driven in the present work by a relatively small number of patients (8 patients experiencing increases in EDSS at a total of 16 visits), we consider it biologically plausible due to the documented effects of autoimmunity on bipolar function [13-21]. Reproduction of this finding in a larger cohort would be desirable.

Our study has a number of limitations. Firstly, the modest size of our patient cohort is likely to have reduced the power of our analyses and may partially explain the predominance of non-significant findings in our results. Mitigating against this, our use of GEE enabled us to include both eyes of patients in our analyses, and thus to analyse a number of eyes comparable to that included in previous studies [8-10]. Given the length (approximately four hours per examination) and longitudinal nature of study visits, it was not feasible to recruit and examine a cohort of healthy control subjects alongside the patients. Additionally, we analysed functional measures only of the outer, rather than inner, retina, for several reasons. Firstly, inner retinal function in patients with MS has already been well described by other authors (e.g. [44-49]), as have VEP findings (e.g. [48-52]). Secondly, the outer retina contains the bipolar cells, whose cell bodies are found in the INL; functional changes to these cells are common in autoimmunity-mediated diseases other than MS, such as birdshot chorioretinopathy [13-17] and autoimmune retinopathy [18-21]. We were, therefore, primarily interested in the potential utility of the ERG as a longitudinal measure of bipolar function (assessed using the ERG b-wave) in MS. An additional consideration is that as the statistical power of our analyses was likely reduced due to the modest number of patients recruited, analysing additional parameters and further correction of multiplicity may have reduced the power of our analyses further.

Our analyses were primarily focussed on ERG peak times. This decision was made based on previous work by our group [7] and others [8-12, 22], in which peak times, and not amplitudes, were typically recorded as abnormal in patients with MS. However, we included rod ERG amplitudes in our analysis due to previous work suggesting longitudinal worsening of this parameter [10] (a finding we were unable to replicate, as discussed above). Additionally, amplitudes appear to be affected by placement of the DTL electrode, whereas peak times are not $[32,33]$; subtle inter-visit differences in DTL position are, therefore, less likely to affect our results. Nevertheless, amplitude data were analysed in the form of the dark- and lightadapted 3.0 (rod-cone and cone, respectively) b-/awave ratios, which have the advantage of being normalised and thus independent of variations in DTL position; these ratios did not change significantly over the study duration.

In conclusion, despite a degree of individual variability, outer retinal function appears to remain approximately stable at the group level over a threeyear period in patients with early or relatively benign MS and CIS. Increased global disability may be associated with bipolar cell dysfunction, although recent non-ON clinical relapses appear unrelated to retinal function. Future investigations may require a large patient cohort and/or an extended study duration 


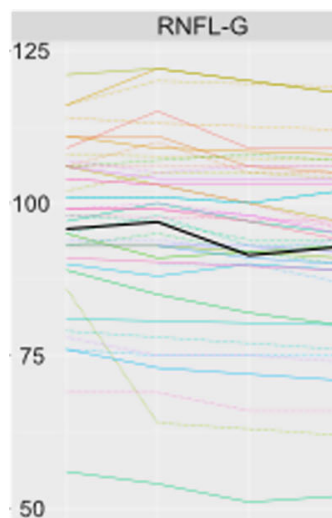

(a) 100

RNFL-T

(b) 80

(c)

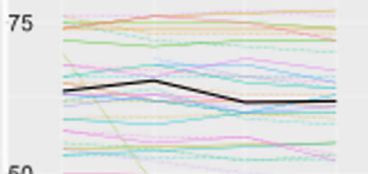

60

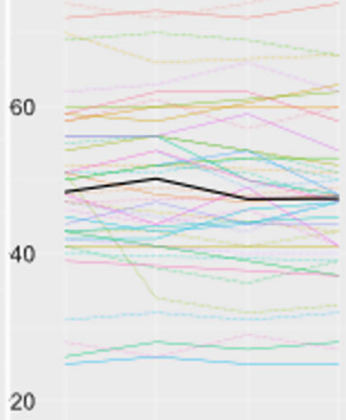

RNFL-PMB

25

(d)

INL
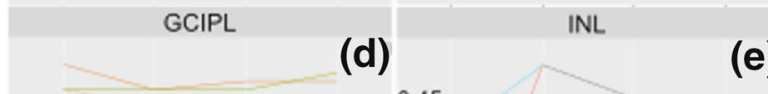

(e)

OPL
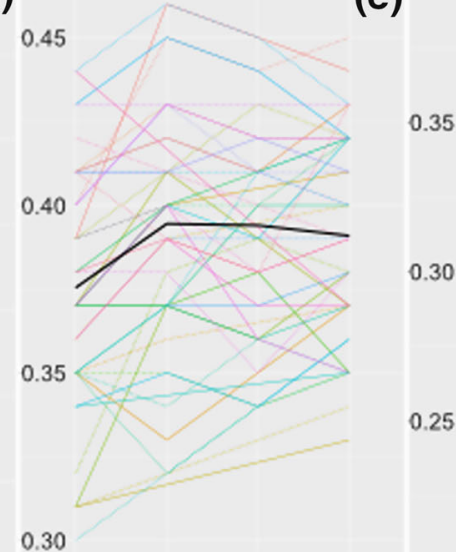

0.8

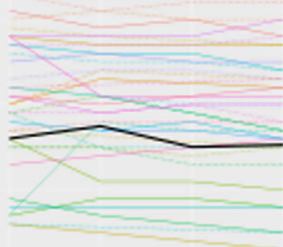

0.6

0.825

ORL

(g)

0.35

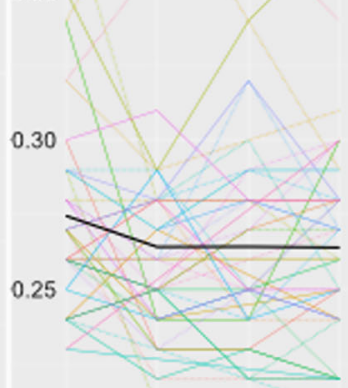

ONL

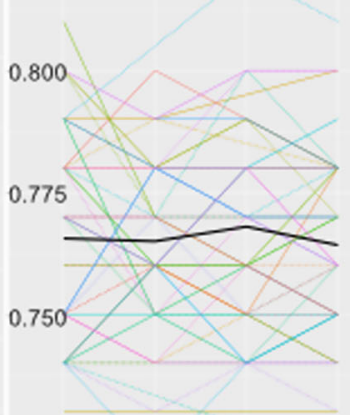

(h)

0.8

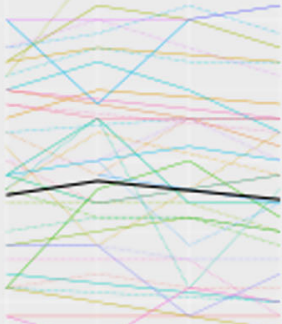

0.6

0.725

0.5

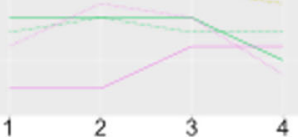


4Fig. 3 a-h Plot showing analysed OCT parameters over the study duration. Coloured lines show the parameters of individual eyes (right eyes: dashed lines; left eyes: solid lines). Individual patients are represented with different colours. Solid black lines show results at the level of the entire cohort (see also Table 3). All parameters at visits 2, 3, and 4 did not differ significantly from baseline (visit 1). G, global average of RNFL thickness; GCIPL, ganglion cell-inner plexiform layer; INL, inner nuclear layer; ONL, outer nuclear layer; OPL, outer plexiform layer; ORL, outer retinal layers; PMB, papillomacular bundle; RNFL, retinal nerve fibre layer; $\mathrm{T}$, temporal quadrant of RNFL

in order to confirm potentially subtle functional changes.

\section{Acknowledgements None}

Author Contributions James V. M. Hanson: methodology, investigation, data curation, writing-original draft, visualization, project administration. Mei-Yee $\mathrm{Ng}$ : formal analysis, visualization, writing-review and editing. Helen K. Hayward-Koennecke: investigation, writing-review and editing. Sven Schippling: conceptualization, writing-review and editing, funding acquisition. Kelly A. Reeve: formal analysis, writing-review and editing, supervision. Christina Gerth-Kahlert: conceptualization, investigation, writingreview and editing, supervision, project administration.

Funding Open Access funding provided by Universität Zürich. Clinical Research Priority Program (CRPP) Multiple Sclerosis, University of Zurich; CRPP Precision MS, University of Zurich; Bruppacher Stiftung; OPOS Stiftung. None of the funding sources had no involvement in study design; in the collection, analysis and interpretation of data; in the writing of the report; and in the decision to submit the article for publication.

Availability of data Pseudonymised data may be provided upon reasonable request by qualified persons in writing to the corresponding author.

\section{Declaration}

Conflicts of interest James V. M. Hanson, Mei-Yee $\mathrm{Ng}$, Helen K. Hayward-Koennecke, Kelly A. Reeve, and Christina Gerth-Kahlert report no conflicts of interest. Sven Schippling is supported by the Swiss MS Society, the Swiss National Science Foundation (320030_175770), and the Myelin Repair Foundation. He has received travel support and/or speaker fees from Biogen, Celgene, Merck, Sanofi/Genzyme and Alexion. He is currently an employee at Roche Pharma, Basel, Switzerland.

Ethical approval The study was approved by the Cantonal Ethics Committee of Zurich (EC-No.2013-0001).
Consent to participate All subjects consented in writing to participating in the study and to their data being published.

Consent for publication All subjects consented in writing to participating in the study and to their data being published.

Open Access This article is licensed under a Creative Commons Attribution 4.0 International License, which permits use, sharing, adaptation, distribution and reproduction in any medium or format, as long as you give appropriate credit to the original author(s) and the source, provide a link to the Creative Commons licence, and indicate if changes were made. The images or other third party material in this article are included in the article's Creative Commons licence, unless indicated otherwise in a credit line to the material. If material is not included in the article's Creative Commons licence and your intended use is not permitted by statutory regulation or exceeds the permitted use, you will need to obtain permission directly from the copyright holder. To view a copy of this licence, visit http://creativecommons.org/licenses/by/4.0/.

\section{References}

1. Thompson AJ, Banwell BL, Barkhof F, Carroll WM, Coetzee T, Comi G, Correale J, Fazekas F, Filippi M, Freedman MS, Fujihara K, Galetta SL, Hartung HP, Kappos L, Lublin FD, Marrie RA, Miller AE, Miller DH, Montalban X, Mowry EM, Sorensen PS, Tintore M, Traboulsee AL, Trojano M, Uitdehaag BMJ, Vukusic S, Waubant E, Weinshenker BG, Reingold SC, Cohen JA (2018) Diagnosis of multiple sclerosis: 2017 revisions of the McDonald criteria. Lancet Neurol 17(2):162-173. https://doi.org/10. 1016/s1474-4422(17)30470-2

2. McDonald WI, Barnes D (1992) The ocular manifestations of multiple sclerosis. 1. Abnormalities of the afferent visual system. J Neurol Neurosurg Psychiatry 55(9):747-752

3. Costello F (2013) The afferent visual pathway: designing a structural-functional paradigm of multiple sclerosis. ISRN Neurol 2013:134858. https://doi.org/10.1155/2013/134858

4. Hanson JVM, Wicki CA, Manogaran P, Petzold A, Schippling S (2020) OCT and multiple sclerosis. In: Gryzybowski A, Barboni P (eds) OCT and Imaging in Central Nervous System Diseases. Springer, Cham, pp 195-233

5. Robson AG, Nilsson J, Li S, Jalali S, Fulton AB, Tormene AP, Holder GE, Brodie SE (2018) ISCEV guide to visual electrodiagnostic procedures. Doc Ophthalmol 136(1):1-26. https://doi.org/10.1007/s10633-017-9621-y

6. McCulloch DL, Marmor MF, Brigell MG, Hamilton R, Holder GE, Tzekov R, Bach M (2015) ISCEV Standard for full-field clinical electroretinography (2015 update). Doc Ophthalmol 130(1):1-12. https://doi.org/10.1007/s10633014-9473-7

7. Hanson JVM, Hediger M, Manogaran P, Landau K, Hagenbuch N, Schippling S, Gerth-Kahlert C (2018) Outer retinal dysfunction in the absence of structural abnormalities in multiple sclerosis. Invest Ophthalmol Vis Sci 59(1):549-560. https://doi.org/10.1167/iovs.17-22821 
8. Sriram P, Wang C, Yiannikas C, Garrick R, Barnett M, Parratt J, Graham SL, Arvind H, Klistorner A (2014) Relationship between optical coherence tomography and electrophysiology of the visual pathway in non-optic neuritis eyes of multiple sclerosis patients. PLoS ONE 9(8):e102546. https://doi.org/10.1371/journal.pone. 0102546

9. Gundogan FC, Demirkaya S, Sobaci G (2007) Is optical coherence tomography really a new biomarker candidate in multiple sclerosis?-A structural and functional evaluation. Invest Ophthalmol Vis Sci 48(12):5773-5781. https://doi. org/10.1167/iovs.07-0834

10. You Y, Graham EC, Shen T, Yiannikas C, Parratt J, Gupta V, Barton J, Dwyer M, Barnett MH, Fraser CL, Graham SL, Klistorner A (2018) Progressive inner nuclear layer dysfunction in non-optic neuritis eyes in MS. Neurol Neuroimmunol Neuroinflamm 5(1):e427. https://doi.org/10. 1212/nxi.0000000000000427

11. You Y, Zhu L, Zhang T, Shen T, Fontes A, Yiannikas C, Parratt J, Barton J, Schulz A, Gupta V, Barnett MH, Fraser CL, Gillies M, Graham SL, Klistorner A (2019) Evidence of Muller Glial Dysfunction in patients with aquaporin-4 immunoglobulin G-positive neuromyelitis optica spectrum disorder. Ophthalmol 126(6):801-810. https://doi.org/10. 1016/j.ophtha.2019.01.016

12. Forooghian F, Sproule M, Westall C, Gordon L, Jirawuthiworavong G, Shimazaki K, O'Connor P (2006) Electroretinographic abnormalities in multiple sclerosis: possible role for retinal autoantibodies. Doc Ophthalmol 113(2):123-132. https://doi.org/10.1007/s10633-006-90220

13. Zacks DN, Samson CM, Loewenstein J, Foster CS (2002) Electroretinograms as an indicator of disease activity in birdshot retinochoroidopathy. Graefes Arch Clin Exp Ophthalmol 240(8):601-607. https://doi.org/10.1007/ s00417-002-0506-7

14. Holder GE, Robson AG, Pavesio C, Graham EM (2005) Electrophysiological characterisation and monitoring in the management of birdshot chorioretinopathy. Br J Ophthalmol 89(6):709-718. https://doi.org/10.1136/bjo.2004. 047837

15. Sobrin L, Lam BL, Liu M, Feuer WJ, Davis JL (2005) Electroretinographic monitoring in birdshot chorioretinopathy. Am J Ophthalmol 140(1):52-64. https://doi. org/10.1016/j.ajo.2005.01.053

16. Kiss S, Ahmed M, Letko E, Foster CS (2005) Long-term follow-up of patients with birdshot retinochoroidopathy treated with corticosteroid-sparing systemic immunomodulatory therapy. Ophthalmol 112(6):1066-1071. https://doi. org/10.1016/j.ophtha.2004.12.036

17. Fuerst DJ, Tessler HH, Fishman GA, Yokoyama MM, Wyhinny GJ, Vygantas CM (1984) Birdshot retinochoroidopathy. Arch Ophthalmol 102(2):214-219

18. Weleber RG, Watzke RC, Shults WT, Trzupek KM, Heckenlively JR, Egan RA, Adamus G (2005) Clinical and electrophysiologic characterization of paraneoplastic and autoimmune retinopathies associated with antienolase antibodies. Am J Ophthalmol 139(5):780-794. https://doi. org/10.1016/j.ajo.2004.12.104

19. Kiratli H, Thirkill CE, Bilgic S, Eldem B, Kececi A (1997) Paraneoplastic retinopathy associated with metastatic cutaneous melanoma of unknown primary site. Eye (Lond) 11(Pt 6):889-892. https://doi.org/10.1038/eye.1997.227

20. Koh AH, Hogg CR, Holder GE (2001) The incidence of negative ERG in clinical practice. Doc Ophthalmol 102(1):19-30

21. Ohta K, Kikuchi T, Yoshida N (2011) Slowly progressive non-neoplastic autoimmune-like retinopathy. Graefes Arch Clin Exp Ophthalmol 249(1):155-158. https://doi.org/10. 1007/s00417-010-1436-4

22. Forooghian F, Adamus G, Sproule M, Westall C, O'Connor $P$ (2007) Enolase autoantibodies and retinal function in multiple sclerosis patients. Graefes Arch Clin Exp Ophthalmol 245(8):1077-1084. https://doi.org/10.1007/ s00417-006-0527-8

23. Graham EC, You Y, Yiannikas C, Garrick R, Parratt J, Barnett MH, Klistorner A (2016) Progressive loss of retinal ganglion cells and axons in nonoptic neuritis eyes in multiple sclerosis: a longitudinal optical coherence tomography study. Invest Ophthalmol Vis Sci 57(4):2311-2317. https:// doi.org/10.1167/iovs.15-19047

24. Abalo-Lojo JM, Treus A, Arias M, Gomez-Ulla F, Gonzalez F (2018) Longitudinal study of retinal nerve fiber layer thickness changes in a multiple sclerosis patients cohort: A long term 5 year follow-up. Mult Scler Relat Disord 19:124-128. https://doi.org/10.1016/j.msard.2017.11.017

25. Balk LJ, Cruz-Herranz A, Albrecht P, Arnow S, Gelfand JM, Tewarie P, Killestein J, Uitdehaag BM, Petzold A, Green AJ (2016) Timing of retinal neuronal and axonal loss in MS: a longitudinal OCT study. J Neurol 263(7):1323-1331. https://doi.org/10.1007/s00415-0168127-y

26. Saidha S, Al-Louzi O, Ratchford JN, Bhargava P, Oh J, Newsome SD, Prince JL, Pham D, Roy S, van Zijl P, Balcer LJ, Frohman EM, Reich DS, Crainiceanu C, Calabresi PA (2015) Optical coherence tomography reflects brain atrophy in multiple sclerosis: A four-year study. Ann Neurol 78(5):801-813. https://doi.org/10.1002/ana.24487

27. Balk LJ, Coric D, Knier B, Zimmermann HG, Behbehani R, Alroughani R, Martinez-Lapiscina EH, Brandt AU, Sanchez-Dalmau B, Vidal-Jordana A, Albrecht P, Koska V, Havla J, Pisa M, Nolan RC, Leocani L, Paul F, Aktas O, Montalban X, Balcer LJ, Villoslada P, Outteryck O, Korn T, Petzold A (2019) Retinal inner nuclear layer volume reflects inflammatory disease activity in multiple sclerosis; a longitudinal OCT study. Mult Scler J-Exp, Transl Clin 5(3):2055217319871582. https://doi.org/10.1177/ 2055217319871582

28. Knier B, Schmidt P, Aly L, Buck D, Berthele A, Muhlau M, Zimmer C, Hemmer B, Korn T (2016) Retinal inner nuclear layer volume reflects response to immunotherapy in multiple sclerosis. Brain. https://doi.org/10.1093/brain/aww219

29. Polman CH, Reingold SC, Banwell B, Clanet M, Cohen JA, Filippi M, Fujihara K, Havrdova E, Hutchinson M, Kappos L, Lublin FD, Montalban X, O'Connor P, Sandberg-Wollheim M, Thompson AJ, Waubant E, Weinshenker B, Wolinsky JS (2011) Diagnostic criteria for multiple sclerosis: 2010 revisions to the McDonald criteria. Ann Neurol 69(2):292-302. https://doi.org/10.1002/ana.22366

30. Costelloe L, Orourke K, Kearney H, McGuigan C, Gribbin L, Duggan M, Daly L, Tubridy N, Hutchinson M (2007) The patient knows best: significant change in the physical 
component of the Multiple Sclerosis Impact Scale (MSIS29 physical). J Neurol Neurosurg Psychiatr 78(8):841-844. https://doi.org/10.1136/jnnp.2006.105759

31. Marmor MF, Fulton AB, Holder GE, Miyake Y, Brigell M, Bach M, International Society for Clinical Electrophysiology of V (2009) ISCEV Standard for full-field clinical electroretinography (2008 update). Doc Ophthalmol 118(1):69-77. https://doi.org/10.1007/s10633-008-9155-4

32. Kurtenbach A, Kramer S, Strasser T, Zrenner E, Langrova $H$ (2017) The importance of electrode position in visual electrophysiology. Doc Ophthalmol 134(2):129-134. https://doi.org/10.1007/s10633-017-9579-9

33. Brouwer AH, de Wit GC, de Boer JH, van Genderen MM (2020) Effects of DTL electrode position on the amplitude and implicit time of the electroretinogram. Doc Ophthalmol 140(3):201-209. https://doi.org/10.1007/s10633-01909733-3

34. Schippling S, Balk LJ, Costello F, Albrecht P, Balcer L, Calabresi PA, Frederiksen JL, Frohman E, Green AJ, Klistorner A, Outteryck O, Paul F, Plant GT, Traber G, Vermersch P, Villoslada P, Wolf S, Petzold A (2015) Quality control for retinal OCT in multiple sclerosis: validation of the OSCAR-IB criteria. Mult Scler 21(2):163-170. 1352458514538110

35. Liang K-Y, Zeger SL (1986) Longitudinal data analysis using generalized linear models. Biometrika 73(1):13-22. https://doi.org/10.1093/biomet/73.1.13

36. Benjamini Y, Hochberg Y (1995) Controlling the False Discovery Rate: A Practical and Powerful Approach to Multiple Testing. J Roy Stat Soc: Ser B (Methodol) 57(1):289-300

37. R Core Team (2018) R: A Language and Environment for Statistical Computing. vol 3.5.3. R Foundation for Statistical Computing, Vienna, Austria

38. Højsgaard S, Halekoh U, Yan J (2005) The r package geepack for generalized estimating equations. J Stat Softw 15(2):1-11. https://doi.org/10.18637/jss.v015.i02

39. Ratchford JN, Saidha S, Sotirchos ES, Oh JA, Seigo MA, Eckstein C, Durbin MK, Oakley JD, Meyer SA, Conger A, Frohman TC, Newsome SD, Balcer LJ, Frohman EM, Calabresi PA (2013) Active MS is associated with accelerated retinal ganglion cell/inner plexiform layer thinning. Neurol 80(1):47-54. https://doi.org/10.1212/WNL. 0b013e31827b1a1c

40. Gabilondo I, Martinez-Lapiscina EH, Fraga-Pumar E, Ortiz-Perez S, Torres-Torres R, Andorra M, Llufriu S, Zubizarreta I, Saiz A, Sanchez-Dalmau B, Villoslada P (2015) Dynamics of retinal injury after acute optic neuritis. Ann Neurol 77(3):517-528. https://doi.org/10.1002/ana. 24351

41. Wicki CA, Manogaran P, Simic T, Hanson JVM, Schippling S (2020) Bilateral retinal pathology following a first-ever clinical episode of autoimmune optic neuritis. Neurol Neuroimmunol Neuroinflamm 7(2):e671. https://doi.org/ 10.1212/nxi.0000000000000671

42. Behbehani R, Adnan H, Al-Hassan AA, Al-Salahat A, Alroughani R (2018) Predictors of retinal atrophy in multiple sclerosis: A longitudinal study using spectral domain optical coherence tomography with segmentation analysis. Mult Scler Relat Disord 21:56-62. https://doi.org/10.1016/j. msard.2018.02.010

43. Petzold A, Balcer LJ, Calabresi PA, Costello F, Frohman TC, Frohman EM, Martinez-Lapiscina EH, Green AJ, Kardon R, Outteryck O, Paul F, Schippling S, Vermersch P, Villoslada P, Balk LJ (2017) Retinal layer segmentation in multiple sclerosis: a systematic review and meta-analysis. Lancet Neurol 16(10):797-812. https://doi.org/10.1016/ s1474-4422(17)30278-8

44. Wang J, Cheng H, Hu YS, Tang RA, Frishman LJ (2012) The photopic negative response of the flash electroretinogram in multiple sclerosis. Invest Ophthalmol Vis Sci 53(3):1315-1323. https://doi.org/10.1167/iovs.11-8461

45. Serra G, Carreras M, Tugnoli V, Manca M, Cristofori MC (1984) Pattern electroretinogram in multiple sclerosis. J Neurol Neurosurg Psychiatr 47(8):879-883. https://doi. org/10.1136/jnnp.47.8.879

46. Hokazono K, Raza AS, Oyamada MK, Hood DC, Monteiro ML (2013) Pattern electroretinogram in neuromyelitis optica and multiple sclerosis with or without optic neuritis and its correlation with FD-OCT and perimetry. Doc Ophthalmol 127(3):201-215. https://doi.org/10.1007/s10633013-9401-2

47. Celesia GG, Kaufman D (1985) Pattern ERGs and visual evoked potentials in maculopathies and optic nerve diseases. Invest Ophthalmol Vis Sci 26(5):726-735

48. Parisi V, Manni G, Spadaro M, Colacino G, Restuccia R, Marchi S, Bucci MG, Pierelli F (1999) Correlation between morphological and functional retinal impairment in multiple sclerosis patients. Invest Ophthalmol Vis Sci 40(11):2520-2527

49. Rodriguez-Mena D, Almarcegui C, Dolz I, Herrero R, Bambo MP, Fernandez J, Pablo LE, Garcia-Martin E (2013) Electropysiologic evaluation of the visual pathway in patients with multiple sclerosis. J Clin Neurophysiol 30(4):376-381. 0b013e31829d75f7

50. Pierelli F, Pozzessere G, Stefano E, Martelli M, Rizzo PA, Morocutti C (1985) Pattern visual evoked potentials and flash electroretinogram in clinically definite multiple sclerosis. Eur Neurol 24(5):324-329

51. Weinstock-Guttman B, Baier M, Stockton R, Weinstock A, Justinger T, Munschauer F, Brownscheidle C, Williams J, Fisher E, Miller D, Rudick R (2003) Pattern reversal visual evoked potentials as a measure of visual pathway pathology in multiple sclerosis. Mult Scler 9(5):529-534

52. Chirapapaisan N, Laotaweerungsawat S, Chuenkongkaew W, Samsen P, Ruangvaravate N, Thuangtong A, Chanvarapha N (2015) Diagnostic value of visual evoked potentials for clinical diagnosis of multiple sclerosis. Doc Ophthalmol 130(1):25-30. https://doi.org/10.1007/s10633014-9466-6

Publisher's Note Springer Nature remains neutral with regard to jurisdictional claims in published maps and institutional affiliations. 